\title{
Review \\ The functions of nerve growth factor and nerve growth factor receptor in wound healing
}

\author{
Masahiko Mori ${ }^{1}$, Toshiro Yamamoto ${ }^{2}$, Takeshi Amemiya ${ }^{2}$, Narisato Kanamura ${ }^{2}$, Tetsunari Nishikawa ${ }^{3}$, \\ Tomoharu Okamura ${ }^{3}$, Akio Tanaka ${ }^{3}$, Shinichiro Sumitomo ${ }^{1}$, Michio Shikimori ${ }^{1}$ \\ ${ }^{\prime}$ Department of Oral and Maxillofacial Surgery, Division of Oral Pathogenesis and Disease Control, Asahi University School of Dentistry, \\ Mizuho, Japan \\ ${ }^{2}$ Department of Dental Medicine, Kyoto Prefectural University of Medicine Graduate School of Medical Science, Kyoto, Japan \\ ${ }^{3}$ Department of Oral Pathology, Osaka Dental University, Hirakata, Japan
}

Abstract: Nerve growth factor (NGF) and nerve growth factor receptors (NGFRs) play important roles in tissue remodeling during the would healing process of the skin, oral and paranasal mucosa, and cornea. The interactions between NGF and NGFRs are influenced by or interact with a number of molecules in the tissue remodeling process, in which key niche components are varieties of growth factors and their receptors, including NGF and NGFR. In addition to those interactions mentioned above, cell-cell contacts as well as cell-matrix interactions have also been considered to promote wound healing events. The present review focuses on the pathophysiological roles of NGF and NGFR in saliva and salivary glands, and in tear and lacrimal glands under inflammatory and tissue remodeling conditions, as well as their expression profiles in various kinds of cells including mast cells, macrophages, lymphocytes, and those involved in angiogenesis. Finally, we describe how the expression modes of NGF and NGFR regulate the peripheral nerve fiber growth and stimulate wound healing or tissue remodeling in the organs or tissues mentioned above as well as in pressure wounds and diabetic skin lesions. Based on these lines of evidence, we emphasize that NGF and NGFR could represent new and powerful regimens for treatment of tissue injuries.

[Oral Med Pathol 2012; 16: 51-65 doi: 10.3353/omp.16.51]

Key words: innervation, nerve growth factor (NGF), nerve growth factor receptor (NGFR), tissue remodeling, wound healing

Correspondence: Toshiro Yamamoto, Department of Dental Medicine, Kyoto Prefectural University of Medicine Graduate School of Medical Science 465, Kajii-cho, Kamigyoku, Kyoto 602-8566, Japan Phone: +81-75-251-5641, Fax: +81-75-251-5641, E-mail: yamamoto@koto.kpu-m.ac.jp

\section{Introduction}

The process of tissue remodeling in epithelium-lined tissues and organs is strongly influenced by growth factors, cytokines, and their secreting host tissues or organs. Following damage of those epithelium-lined tissues, both epithelial and mesenchymal tissues may migrate and differentiate into mature cells, and this process is usually termed wound repair. Histological structures of the mucosa and skin are different from each other: the skin is composed of the epidermis, dermis, subcutis, and associated skin appendages, in which hair follicles cells have multiple differentiation potential. The mucosal tissue in the oral cavity and nasal-paranasal cavities is composed of nonkeratinized stratified squamous epithelium, lamina propriae, and submucosa, the latter two zones consisting of connective tissue, while the cornea is composed of only corneal epithelium. The process of epithelial repair is generally influenced by the status of the underlying granulation tissue, in which matrix formation and angiogenesis are initially processed by fibroblasts, endothelial cells, and inflammatory cells including macrophages. Repair of connective tissue is advanced and connective tissue matrix formation occurs in the wound bed, while proliferation of epithelial cells is found in the wound surface. As for the direction of wound remodeling, stem cells appear to be positioned for communications with both regenerating epithelial cells and mesenchymal cells. In this respect, Discher et al. reviewed the role of stromal stem cells in tissue regeneration and wound repair (1). This review is a contemporary scientific 
response to the oldest concept of Aulus Cornelius Celsus, who indicated in his first report that human tissue responds to injuries and inflammation as tumor, color and dolor. Those complex phenomena correspond to growth factors secreted from injured tissue or glands; in the case of oral and corneal wounds, the source of growth factors should be salivary and lacrimal glands. A variety of growth factor studies have disclosed that those secreted growth factors, either intrinsic or extrinsic, strongly influence wound healing (2). The present review deals with the influence of nerve growth factor (NGF) and receptor (NGFR) on wound healing and repairing processes. Nerve growth factor (NGF) and epidermal growth factor (EGF) from mouse submandibular gland were first discovered by Levi-Montalcini in 1960 and her subsequent characterization was recognized by the Nobel Prize in Medicine and Physiology in 1986 (3).

In ancient Greece about 2000 years ago, people applied snake saliva to open wounds to enhance cutaneous wound healing. Dogs and domestic animals lick open wounds, a behavior that may enhance wound healing. Whether or not NGF in saliva and tears influences oral and corneal wound healing has not been clarified, although EGF in the saliva suggests a role of maintenance of oral health or enhancing wound healing in the oral mucosa. A new concept of tissue regeneration, known as the niche interaction, has indicated that coordinated interactions with factors, cells, and extracellular matrices define a local biochemical and mechanical niche with a complex regulation that stem cells sense. Key niche components and interactions that participate to regulate stem cell survival, self renewal, and terminal differentiation include growth factors, cell-to-cell contacts, and cell-matrix adherence (4). The present review deals with the biological roles of nerve growth factor (NGF) and nerve growth factor receptors (NGFR) in healing and remodeling processes, as a peripheral interaction, in both corneal and oral-nasal mucosa, and in skin wounds. Regeneration of NGF and NGFR promotes wound remodeling, and this mechanism may provide therapeutic benefits.

\section{Biophysiology of NGF and NGFR}

\section{Biosynthesis of NGF}

NGF from the male mouse submandibular gland is a $7 \mathrm{~s}$ complex formed by 3 subunits, $\alpha, \beta$ and $\gamma$, and all the subunits are molecularly characterized. Biologically active NGF appears to be the $\beta$-subunit, which exists as a 26,000 -dalton homodimer. $\beta$-NGF is synthesized as a prepromolecule that undergoes subsequent proteolytic cleavage at both amino and carboxyl termini to liberate the mature growth factor.

\section{Nerve growth factor receptor (NGFR)}

Brain-derived neurotrophic factor (BDNF) and neurotrophin 3 (NT-3) are structurally related to NGF. Two classes of receptors for NGF have been identified by their distinct affinities. The low affinity receptor is $75 \mathrm{~K}$ cysteine-rich glycoprotein encoded by characterized LNGFR gene, and the high affinity receptor is a $140 \mathrm{~K}$ tyrosine protein kinase encoded by the trk proto-oncogene $\left(\mathrm{gp} 140^{t r k}\right)$ that binds NGF with high affinity. gp $140^{\text {trk }}$ is a functional NGF receptor (5-6). The spatial patterns of distribution of neurotrophic factors; NGF, BDNF, neurotrophin 3 (NT-3) and glial cell line-derived neurotrophic factor (BDNF), and their receptors' (p75 NIGR, trkA, trkB and trkC) mRNA levels in the human peripheral nervous system and nonneural tissues are largely similar to those reported in other mammals (7). It has been reported that trigeminal ganglion and other neuronal nucleus expressed NGF and low (P75) and high affinity receptors (TrkA, TrkB, and TrkC). NGF is an elaborated trigeminal neurostructure which coexpresses both P75 and TrkA receptors (8). The interaction between NGF and receptor can be inhibited either on the level of ligand by altering NGF conformation so that NGF is no longer recognized by the receptor or on the level of receptor by blocking the binding site of $p 75$ and trkA gene products (9). NGF released systemically or locally in glands, keratinocytes, mast cells, and lymphocytes is recently established to have functional roles as growth factors for epithelial and mesenchymal tissues and further participates in tissue remodeling.

Peters et al. described the new concept that NGF operates like a double-edged sword in cutaneous biology and promotes proliferation in cell populations yet promotes apoptosis in others, depending on their neurotrophin receptor co-expression pattern, in experiments with P75 receptormediated signaling which promotes human hair follicle regression (catagen) (10). These murine data raise the expectation that NGF via trkA and/or $p 75^{\mathrm{NTR}}$ signaling acts as a potent hair growth modulator in humans. Keratinocytes in the hair follicle initiate epidermal proliferation at cutaneous injuries. The TrkA receptor is activated primarily by NGF and it can be activated by a high concentration of neurotrophin 3 (NT-3). NGF binds to TrkA, brain-derived neurotrophic factor (BDNF), and neurotrophin 4 (NT-4) binds to TrkB, and NT-3 binds to TrkC. TN-3 also binds TrkA (and TrkB) and can activate trkA signaling and cellular responses. The pan-neurotrophin receptor $\mathrm{P} 75^{\mathrm{NTR}}$ strongly inhibits activation of $\operatorname{trk} A$ by NT-3 but not by NGF. NT-3 does not activate trkA signaling pathways in PC12 cells unless $p 75^{\mathrm{NTR}}$ levels are reduced, suggesting that $p 75^{\mathrm{NTR}}$ directly suppresses the ability of $\operatorname{trkA}$ to respond to NT-3. Mischel et al. indicated that $\mathrm{P} 75^{\mathrm{NTR}}$ and TrkA could be coimmunoprecipitated from Xenopus oocytes, and suggested that interaction of two receptors on the cell surface mediated the inhibition of NT-3 activated signaling through $\operatorname{trkA}(11)$. NGF interacts with two structurally-unrelated receptors, TrkA receptor-tyrosine kinase and $\mathrm{P} 75$, one of the tumor necrosis factor receptor (TNFR) family members. Each receptor binds independently to NGF with predominantly low affinity $\left(\mathrm{Kd}=10^{-9} \mathrm{M}\right)$, but they produce high affinity binding sites $\left(\mathrm{Kd}=10^{-11} \mathrm{M}\right)$ upon receptor co-expression. Extracellular domain mutations of P75 that abolished NGF binding still generated high affinity binding with TrkA, and these findings indicate that the transmembrane and cytoplasmic domains of TrkA and P75 are responsible for high affinity site formation and suggest that P75 alters the conformation of TrkA to generate high affinity binding (12). 
It has been reported that neurotrophin receptors TrkA, TrkB and TrkC have been detected in the normal nonneuronal tissues of adult human. Marked reactivity of TrkA is found in the skin epidermis, epithelium of uterine cervix, luminal epithelium of the breast, the epithelium of the fallopian tube, the luminal epithelium of the prostate and the esophagus epithelium. In the skin, TrkA and TrkB/TrkC are present in the basal and granular layers of epidermis respectively (13).

NGF, brain-derived neurotrophic factor (BDNF), neurotrophin 4 (NT-4) and neurotrophin 3 (NT-3) initiate their function by binding to trk receptors and $\mathrm{P} 75^{\mathrm{NTR}}$. Functionally signaling by trk $A$ and $\mathrm{p} 75^{\mathrm{NTR}}$ may be synergistic, independent or antagonistic. The biological role of NGF and both TrkA and P75 receptors and their contribution in the complex network of tissue remodeling or wound healing, is revived in the present paper. NGF and their receptors represent an advance in future treatment modalities of etiologically different ulcers (pressure ulcers in skin, corneal ulcer, chemical burns, and oral mucosal ulcers) and may shorten recovery in the process. NGF and NGFR might open new possibilities along with other growth factors in healing processes in several pathological conditions (14).

\section{NGF and NGFR in hair follicle cells and keratinocytes}

Epidermal stem cells are self-renewing and generate transit amplifying cells that exit the cell cycle and division and undergo terminal differentiation that lead to the formation of the hair follicle, inter-follicular epidermis and sebaceous gland. Botchkarev et al. pay attention to the epidermal cell remodeling system looking at hair follicles in the involvement of NGF, brain-derived neurotrophic factor (BDVF) and neurotrophin 4 (NT-4), although in the skin NGF controls not only the development of targeted peripheral innervation but also stimulates keratinocytic proliferation (15). The expression of BDNF and NT-4 has been shown to be hair cycle dependent, and it peaked during spontaneous and apoptosis-derived hair follicle regression (catagen). During catagen, BDNF in RNA and protein NT-4 were expressed in the regressing hair follicle compartment, whereas trkB in RNA and protein were seen in dermal papilla fibroblasts, epithelial strands and hair stem cells. These results may contribute neurotrophic factors involving keratinocytic remodeling in skin wounds.

\section{Antiapoptotic affect}

Binding of NGF to trkA receptor is considered to have an antiapoptotic effect. Biological studies indicate that NGF induces atypical apoptosis that is abrogated by tyrosine kinase inhibitor K252 $\alpha$, but not by an inhibitor of NGF-P75 binding, in trkA-transfected PC12 cells (16). There are two unique functions of the high affinity heteromeric NGF receptor site: i) integration of both the MAPK (mitogenactivated protein kinase) and Akt pathways in the production of NGF-induced neurite outgrowth; and ii) rapid and sustained activation of the Akt pathway, with consequent longterm cellular survival. Interaction in the $t r k A / p 75^{\mathrm{NTR}}$ heteromeric receptor signal transduction network was revealed, i.e.
NGF-induced activation of the MAPK pathway appears to inhibit the parallel NGF-induced Akt pathway (17).

\section{Skin color, melanocytes and NGFR}

Skin color results from its melanin content and distribution, and exposure to UV irradiation stimulates treated pigmentation to protect against photodamage. Human melanocytes reportedly express the NGFR (P75) in vitro because melanocyte migration is regulated in part by NGF. In addition, cultured human keratinocytes produce NGF. Melanocyte stimulation with phorbol ester (TPA) induces NGFR (P75) and also induces trk in melanocytes, and the TPA effect is potentiated by the presence of keratinocytes in culture. Behaviors of human skin melanocytes are influenced by NGF, which acts through its high affinity receptors in both keratinocytes and fibroblasts (18).

\section{NGF in salivary gland and lacrimal gland}

\section{NGF in saliva and salivary gland}

Since discovery of the expression of NGF and EGF in the submandibular gland of mice and rats and of the contents of these growth factors in saliva, the effect of saliva on promoting wound closure has been observed in oral mucosal wounds. In an experiment, mice were classified into three groups: i) sialectomy (submandibular glands (SMGs), sublingual glands (SLGs), and parotid glands), ii) duct ligation, and iii) sham operation (19). The authors pointed out that the healing process of wounded mice may involve communal licking of the wound, and this may prompt a healing effect by growth factors (NGF and EGF) in saliva. The saliva of mice contains a higher concentration of NGF and EGF, and their wound licking corresponds to a topical application. Application of NGF and EGF, as well as opening of the wound, may accelerate closure. Murphy et al. reexamined NGF levels in the serum and saliva in both male and female mice, and SMGs of male mice contained more NGF than did those of female mice (20). Moreover, no sex difference in circulating NGF was observed. Serum NGF did not change after submandibular gland removal or after administration of autonomic agonists. Highest NGF levels are normally secreted in the mice saliva at levels that reflect the sex differences in NGF of the SMGs, and it is suggested that NGF in the saliva may play a biological role for regulating wound healing. On the contrary, salivary EGF is a strong inhibitor of gastric acid secretion and it is probably identical to urogastrone, which has been known to promote wound healing of induced gastric ulcers (21).

Variations in NGF levels in the normal serum of humans have been reported according to age and gender (22-23). Concentrations of NGF in the saliva have also been noted in rodents (24) and humans (25-26). Nam et al. pointed out that salivary NGF levels in humans were affected by age and gender (27). Mean levels of NGF are $901.4 \pm 75.6 \mathrm{pg} / \mathrm{ml}$ in resting whole saliva, $885.9 \pm 79.9 \mathrm{pg} / \mathrm{ml}$ in stimulated parotid saliva, and $1066.1 \pm 88.1 \mathrm{pg} / \mathrm{ml}$ in stimulated SMG / SLG saliva. The NGF concentration of resting saliva and stimulated parotid saliva are significantly higher in women 
than men, and that of stimulated SMG saliva is significantly higher than the stimulated parotid saliva and significantly correlated with the stimulated parotid saliva NGF level. The results of this study were obtained from a total of 127 healthy volunteers, consisting of 64 males and 63 females, and NGF levels were measured with enzyme immunoassay.

A recent study by Komatsu et al. measured NGF levels in 93 healthy volunteers ( $35 \mathrm{~m}$ and 58fe) aged 18-87 years, and stimulated saliva was collected during gum chewing. Saliva secretion per minute and NGF concentration per unit volume were measured by enzyme-linked immunosorbent assay (28). The mean NGF in saliva was $55,70 \pm 38,27 \mathrm{pg} /$ $\mathrm{ml}$, and no relationship was found between NGF concentration and aging, gender and the number of retained teeth. The NGF level decreased with age, particularly for participants 70 years and older, and it was higher in males than females.

The cells of GCT segment of SMGs in mice and rats are the main source of growth factors (NGF, EGF), and striated ducts in human SMG and SLG are also positive for hEGF (29). NGF concentrations of the human saliva were $9644 \mathrm{pg} /$ $\mathrm{ml}$ by Ruhl et al. and Nam et al. found them to be lower than those of Ruhl's study and mean NGF in saliva was $84.38 \pm$ $71.06 \mathrm{pg} / \mathrm{min}$ by Komatsu (26-28). The previous three studies demonstrated human saliva contains NGF, so wound healing in the oral mucosa could be the direct effect of salivary NGF, as well as EGF.

It has been noted that NGF was synthesized and secreted by pancreatic $\beta$ cells in the adult rat, and NGF secretion increased in response to elevated glucose or potassium, but that it developed in response to dibutyryl-cAMP. The $\operatorname{trk} A$ receptors also present in $\beta$ cells and trkA mRNA are modulated by NGF and dibutyryl-cAMP. This result suggests the biological roles of $\beta$ cell NGF which in turn could be related to the diagnosis of diabetes mellitus (DM), when serum NGF levels are diminished (30).

\section{NGF in lacrimal gland}

Dry eye conditions have been known to damage the ocular surface and this in turn leads to further damage to the lacrimal gland. Lacrimal gland functions, including secreting growth factors (NGF), and the ocular surface are integrated with one another (31). Nguyen et al. examined growth factors and receptor mRNA, TGF- $\beta 1, \beta 2, \beta 3$ and TGF- $\beta 3 R$; FGF and FGF-R1; $\beta$-NGF, 75NGF-R, and PDGF-AA, PDGF-BB in human lacrimal gland (32). They suggested that those growth factors including NGF and NGFR may have autocrine and paracrine roles in modulating the lacrimal gland, and their absence may play a role in pathologic states in ocular tissues. Rabbit lacrimal gland contains HGF, KGF and EGF mRNAs, and those growth factors increase following corneal wounding (33). Factors in tear fluid trigger keratinocyte loss after removal of the epithelium in the mouse cornea (34).

\section{NGF in conjunctiva}

Lambiase et al. reported that with conjunctive biopsies $(n=10)$ and corneal specimens $(n=5)$, immunohistochemical detection of NGFR (TrkA) was performed, and in healthy conjunctival specimens, basal cells were strongly expressed and stromal cells (rare) were also positive for NGFR (TrkA) (35). The human ocular surface is positive for NGFR. NGF induced the expression of $\mathrm{P} 75^{\mathrm{NTR}}$ in fibroblasts that expressed only TrkA ${ }^{\mathrm{NGF}}$ and increased the migration of wound fibroblasts, although NGF did not enhance their proliferation and collagen biosynthesis. Chronic NGF treatment induced TGF- $\beta 1$ production by fibroblasts, and following specific TGF- $\beta$ neutralization, all the NGF-induced effects were completely abrogated (36).

\section{NGF and NGFR in corneal epithelium}

Existence of EGF and NGF in the saliva is a key role of oral health and the regulation of wound healing of the oral mucosa. Similarly, NGF in the tear film and corneal epithelium is hypothesized to play an important role in ocular surface maintenance and corneal wound healing (37). It has been reported that NGF levels in normal dog tears, corneal epithelium, third eyelid gland and lacrimal gland were $15.4 \pm 4.6 \mathrm{ng} / \mu 1.33 .5 \pm 12.3,52.4 \pm 17.4$ and $48.8 \pm 9.4$ $\mathrm{ng} / \mu \mathrm{l}$, respectively, and immunohistochemically, NGF and TrkA were detected in all tissues examined. After unilateral corneal wounding, NGF concentration increased in the tears bilaterally for 3 days, particularly in wounded eyes, and then returned to pre-wound values. NGF and trkA receptor increased significantly in ipsilateral cornea epithelium following unilateral wounding. NGF and TrkA are present under normal conditions in canine tears, and lacrimal and third eyelid glands. NGF is elevated in the tears, cornea and lacrimal gland after corneal epithelial wounding; however, topical application of NGF or its blocking antibody does not modulate corneal wound healing in the normal dog eye.

\section{NGF and NGFR in wound healing}

\section{Wound healing and tissue remodeling}

Modulation in wound healing has been an interesting subject in regard to pathophysiological aspects such as the acute and chronic phase of the healing mechanism. In pharmacological treatments for wound healing for tissue remodeling, new approaches using growth factors and cytokine has been the main focus. Topically applied growth factors have the potential to influence the healing process in wound, and in ulcer of mucosa and skin and fractured bone (38). Diegelmann and Evans classified wound healing into 3 phases, acute, fibrotic, and delayed healing, particularly treatment remodeling of chronic non-healing ulcers, which has always posed problems from a clinical standpoint (39). Pathologic figures of non-healing pressure ulcers in the skin, and injured ulcers caused by dental prosthesis, and oral mucositis after radiation therapy or chemotherapy in cancer patients are characterized by the existence of chronic inflammatory cells associated with destructive enzymes and reactive oxygen. For connective tissue repair, it is essentially important to recover modulation of fibroblastic cells to the myofibroblastic phenotype (40).

It has been interesting to note that the effect of moist and 
moist exposed dressing on wounds shows faster healing. Atiyeh et al. reported that improved healing of full (or partial) thickness cutaneous wounds in wet and moist environments is due primarily to retention of biological fluids over the wound preventing desiccation of denuded dermis or deeper connective tissues. This means that migration of keratinocytes occurs over the wound surface and enables the naturally-existing growth factors and cytokine to exert beneficiary effects on wound reepithelization as well as contraction (41). The same authors denoted that scar formations involve 3 processes for healing wounds; scar quality is significantly superior in those wounds treated with moist exposed burn ointment, or MEBO (42). Non-adeninebased purines (NABPs) are known to promote cell proliferation and release of growth factors (NGF). Jiang et al. studied the effect of NABPs on wound healing (43). Cotreatment of wounds with guanosine plus anti-NGF reversed the guanosine-promoted acceleration of wound healing, indicating that the effect of guanosine is mediated in part by NGF. The NABP-mediated acceleration of skin wound healing is mediated via an NGF-dependent mechanism, and this finding provides a useful approach for the treatment of clinical wounds.

The wound healing process is pathologically divided into 3 phases: the 1st stage is an acute response to tissue injuries or damage such as a surgical or incised wound, burns and chemical injuries, and physical injuries such as pressure and freeze wounds; the 2 nd stage is a reactive phase to affected injuries which are usually inflammatory reactions; and the $3^{\text {rd }}$ stage involves remodeling phases. During healing processes, many biological growth factors, including NGF, regulate wound tissues and accelerate healing. The present review has noted the roles of biophysiological functions in wound healing on the cornea, keratinocytes in the skin, oral and nasal mucosa, burn and pressure wound, and also tissue repair process.

\section{NGF and NGFR in the cells related to wound healing}

Mast Cells: Aloe and Levi-Montalcini in 1977 first described that injection of NGF to neonatal rats increased the mast cell numbers in various tissues (44). NGF induces development of mast cells in the connective tissue from bovine bone marrow (45). It is reported that NGF released from fibroblasts in local tissues may play a putative role in relation to connective tissue-type mast cells and basophils (46-48). NGF also suppresses apoptosis of rat PMCs (peritoneal mast cells) through p140trk tyrosine phosphorylation and possessed proliferation activity. NGF may act as a key factor to promote survival of connective tissue type mast cells (49). NGF appears to induce the phenotypic change to connective tissue type mast cells (CTMC), and in cultured bone marrow-derived mast cells (BMDMC), 3T3 fibroblasts and IL-3, the phenotypic change of BMCMC to CTMC was found. Neither BMDMC alone nor IL-3 alone increased the concentration of NGF. It is possible that BMDMC stimulated by IL-3 may induce the production and/or release of NGF by fibroblasts (45). Biological activity of NGF is mediated via two types of cell surface receptors with different affinities: the low affinity NGF receptor is a $75 \mathrm{KD}$ glycoprotein. The high affinity receptor is a $140 \mathrm{KD}$ nucleolar containing a tyrosine kinase domain that is encoded by the trk protooncogene, which has been isolated from human colon carcinoma.

Mast cells concentrate at an inflammatory or injury site, which suggests that they play a critical role in wound healing or tissue repair. The absence of mast cells has no effect on proliferating aspects of wound healing including reepithelialization, angiogenesis and collagen formation; furthermore, mast cells are known to release VEGF and proangiogenic mediators. Mast cells modulate the recruitment of neutrophil into sites of injuries, yet are unlikely to exert a major influence on proliferative changes within wound healing sites (50).

It is generally accepted that under normal physiological conditions, mast cells in the skin and oral mucosa localize around peripheral nerves, blood vessels and hair follicles in the skin, and in minor salivary glands in the oral mucosa. This histological feature of mast cell distribution suggests that multifunctional evidence is seen at local areas in the skin and mucosa, possibly indicating that immunological environmental processes may be involved in subepithelial connective tissue. Recently, mast cell function has been clarified in the normal skin and mucosa, as well as in diseased areas including allergic injury and wound healing. Among them, the study of mast cell-derived NGF and NGFR has increasingly given new insights for tissue remodeling research (51). Mast cells contribute significantly to the cytokine network of wound repair via MC-derived IL-4 and stimulation of fibroblast proliferation (52). It is interesting to note that mast cells and eosinophilic leucocytes are a source of NGF as key cells of allergic inflammation, so that NGF modulates an allergy-specific response and also tissue repair (53). The same group has investigated that NGF involvement is implied in allergic ocular diseases (54).

Macrophages: Macrophages are derived from bone marrow precursors and distributed widely in tissues and in the peripheral blood, and they provide the host defense mechanism for support of host defense against infections and also of homeostasis. The presence of NGF-positive macrophages indicates increased phagocytosis of both nonspecific hydrophilic microspheres and blood cells opsonized with anti-SRBC (sheep red blood cell) antibodies. The addition of NGF to peritoneal macrophages and monocyte-macrophage (J774A1) cells leads to a significant release of IL-1 $\beta$ in a dose-dependent manner, expressing IL-1 $\beta$ mRNA. NGF activity stimulating murine macrophages may be mediated through $\mathrm{p} 140^{\text {trk }}$. NGF may also act as an activator for macrophages in the process of inflammation and immune functions (55). Human monocytes/macrophages infected in vitro with HIV-1 are able to produce substantial levels of NGF that are associated with enhanced expression of high affinity NGF receptor (p140 ${ }^{\text {trk }}$ ) on the cell surface. Treatment of HIV-infected macrophages with anti FGF Ab blocking the biological activity of NGF leads to a marked decrease in the expression of $\mathrm{p} 140^{\text {trkA }}$ receptor (high affinity), a concomitant increased expression of $\mathrm{P} 75^{\mathrm{NTR}}$ (loco-affinity 
receptor) of NGF, and apoptotic death of macrophages (56).

Lymphocytes and leucocytes: NGF enhances both T-and B-cell mediated immune responses (57-58). NGF also promotes growth survival and functional activities of murine neutrophils, chemotaxis, phagocytosis and superoxide production (59-60). NGF is produced by many cell sources such as T cells (61) and memory B lymphocytes. Production of NGF is assessed in cultures of human T and B cells and macrophages, and it is constitutively produced by B cells only, which express $p 140^{r t k A}$ and $p 75^{\text {NGF-R }}$ proteins. In vivo administration of neutralizing anti-NGF antibodies causes a strong reduction in the titer of specific $\operatorname{IgG}$ in mice immunized with tetanus toxoid, nitrophenol or arsonate and reduces the numbers of surface $\mathrm{IgG}$ and $\mathrm{IgA} \mathrm{B}$ cells. NGF is an autocrine survival factor for memory B cells (62). Wound healing processes are usually associated with inflammatory responses against mechanical injuries as well as infections by microorganisms. Inflammatory conditions are essential to cause cell infiltration from lymphocytes, macrophages and mast cells, and they are also related to emergence of NGF and NGF receptor activities.

NGF in connective tissue: It is known that NGF is expressed on the fibroblasts of connective tissue (63-64), on osteoblasts (65-66), on endothelial cells (67) and on tissue homeostasis and widespread distribution, as well as in NGFR in all almost peripheral tissue (68), and that it provides multiple stimulating effects. NGF also stimulates the production of VEGF (vascular endothelial growth factor) in endothelial cells (69).

It is generally accepted that, in nervous tissues, hypoxia increases neural function and eventually enhances synaptic activities and stimulates neoangiogenesis. Calzà et al. reported histological and histochemical features of neuronal hypertrophy, and that endothelial cell hyperplasia were associated with stromal hypotrophy and vascular bed enlargement (ECAM-1) in 6OHDA/NGF-treated superior cervical ganglia (70). The normal wound healing process includes neoangiogenesis and tissue remodeling of both connective and epithelial tissues. In those events, vascular endothelial growth factor (VEGF) and basic fibroblast growth factor (bFGF) play major roles in wound healing, particularly in the early course of tissue remodeling. bFGF and VEGF show potent migratory activities in undifferentiated mesenchymal cells in wound beds and promote fibroblastic differentiation and angiogenesis (71). Upregulation of VEGF production in wound repair has been shown in keratinocytes on epithelial (skin and mucosal) wounds in animal models. NGF control of neuronal expression of angiogenetic and vasoactive factors is a new concept in the wound repair process.

Angiogenesis: Levi-Montalcini originally noted that NGF administration prevents nerve cell degeneration induced by 6-hydroxy-dopamine (6-OHDA) that causes a selective and reversible destruction of sympathetic nerve endings in adult animals, widespread lesions in cells, and neuronal cell death in newborn animals. NGF is a neurotrophin that also plays a role in promoting growth differentiation and stimulates function in sympathetic nerves. Moreover NGF has been recognized as a pleiotropic molecule involved in a variety of peripheral action, such as inflammatory skin lesions and tissue regeneration (70). These evidences further suggest that NGF may mediate endothelial cell proliferation and also promote wound healing. NGF alone and in combination with other growth factors could exert an action on endothelial cells and on angiogenic activation $(69,71)$.

NGF-induced MMP expression could result in the degradation of vascular plaque matrix, weakening of the plaque, and subsequent plaque rupture. Neutrophins (NGF) promote multiple biological responses in smooth muscle cells that could contribute to remodeling the pathway of vascular lesions. The NGF/trk receptor system, by virtue of potent chemotactic activity for smooth muscle cells and its ability to induce MMP-9 expression, is a critical mediator in the remodeling that occurs in the vascular cell in response to injury (72). The role of NGF in inflammation is important, and its effect is involved in endothelial cell proliferation and intercellular adhesion molecule expression by endothelial cells. There is a significant increase in proliferation of microvascular endothelial cells stimulated with NGF as compared to costimulated human dermal microvascular endothelial cells. Raychaudhuri et al. demonstrated the role of NGF in two important aspects of inflammation, i.e., angiogenesis and inflammatory cell recruitment at the site of inflammation (73). Autocrine and/or paracrine NGF may act as a survival factor for the endothelial cell by inhibiting the cell cycle program. NGF might promote cell survival but not cell proliferation of aortic endothelial cells, and inhibition of NGF activity might increase MTT activity by facilitating cell cycle progression (74). NGF plays a crucial role in angiogenic molecules which exert a variety of effects in the cardiovascular system and endothelial cell biology. NGF may contribute to maintenance, survival and function of endothelial cells by autocrine and/or paracrine mechanisms (75).

NGF in keratinocytes: Biosynthesis of NGF has been demonstrated in the developing skin of the mouse embryo. Normal human keratinocytes produce and secrete NGF, and NGF synthesis is confined to the basal cells and is regulated by corticosteroid. Mature stratified squamous epithelium showed specific NGF staining of Golgi apparatus in basal cells. NGF in keratinocytes was secreted as assessed by neuritis induction in sensory neurons obtained from chick embryonic dorsal ganglia. Paracrine of NGF in keratinocytes might have a major role in regulating innervation, lymphocyte activity and melanocyte growth during wound healing (76). During wound healing of human skin, a widespread sprocketing of sensory nerve fibers was observed, and this has an important role in the reepithelialization of the wound. Pincelli et al. noted that NGF synthesized in skin basal cells, and expressed low-affinity NGF-R. Moreover, normal human keratinocytes in the culture express both low- and high-affinity NGFRs at the mRNA levels (77). The NGF effect on human keratinocytes is mediated by high-affinity NGFR, and NGF is secreted by keratinocytes in increasing amounts during cell growth. It is 
reported that the effect of murine NGF on keratinocyte proliferation in intact skin derived from two defined stages of the murine NGF hair cycle, and 10-200 $\mu \mathrm{g} / \mathrm{ml} \mathrm{NGF}$ stimulated keratinocyte proliferation on the organ culture. Follicle keratinocyte proliferation was stimulated by $100 \mathrm{ng} /$ $\mathrm{ml}$ NGF in skin organ cultures. Hair cycle dependent effect of NGF on keratinocyte proliferation in situ may require the presence of mast cells (78).

$N G F, N G F R$ in neural and Schwann cells: Neural crestderived Schwann cells are capable of synthesizing both NGF and NGF-R at levels determined in part by maturity and injury. Human melanocytes express NGF receptor (p75) and NGF stimulate melanocyte gene expression (79). NGF is a regulatory molecule during skin inflammation and remodeling, affecting both the neuronal and immune system, and NGF and both high- and low-affinity receptors have been expressed in keratinocytes (80). NGF prevented cleavage of enzyme poly ADE-ribose polymerase induced in human keratinocytes by ultraviolet B (81). Keratinocytes and corneal fibroblasts of the bovine synthesized proteoglycans in their primary cultures, and the produced proteoglycans may regulate environmental conditions to maintain cutaneous and ocular status (82). NGF significantly increased HFL-1 chemotoxis of human fibronectin and PDGF-BB by $41.8 \% 11.4 \%$ and $47.7 \% \pm 6.6 \%$, respectively. NGF appeared to affect the rate of migration, and its effect was blocked by the tyrosine kinase receptor A inhibitor $\mathrm{K}-252 \mathrm{a}$, suggesting that the biological role of NGF on fibroblast chemotoxis is mediated through the tyrosine kinase receptor (83).

\section{Wound healing of oral and nasal mucosa}

It has been already accepted that wound healing in oral mucosa has a fast recovery compared to that in skin wounds. Oral mucositis is a painful adverse effect in patients receiving radiation and/or anticancer drug therapy, and a common lesion following those treatments. Sonis revised the biology and therapeutic opportunities of oral mucositis so that at the present time there are no effective treatments and thus no opportunity to apply NGF and NGFR for treating oral mucositis (84). Such therapies with EGF and $\beta$-FGF have been applied to topical treatments with successful results (85). Recently, expression of NGF and NGFR in the normal human oral mucosa has been described: cultured normal human oral keratinocytes express mRNA for NGF- $\beta$, proNGF, and their receptors TrkA and P75 ${ }^{\mathrm{NTR}}$, and contain several NGF proforms with molecular weights of 32-114 KDa. Immunostaining of oral mucosa shows pro NGF in all epithelial layers and NGF was found in granular and upper spinous layers. TrkA staining is found in basal and parabasal cells, and a weak and moderate reaction in spinous and granular cells, and P75 ${ }^{\mathrm{NTR}}$ staining is seen in basal cells. These findings suggested that differential expression of NGF and NGFRs throughout the oral epithelia could play a role in epithelial differentiation (86). Histological features during oral mucosal wound healing show that basal cell-like epithelial cells proliferates from the wound edge and these proliferating oral keratinocytes migrate and differentiate into mature squamous epithelium, which suggests that those proliferating epithelial cells (undifferentiated keratinocytes) might express NGFR (TrkA and P75 ${ }^{\mathrm{NTR}}$ ). Furthermore, since human saliva contains NGF as well as EGF, wound healing in the oral mucosa, including aphthous lesions, may be more accelerated than that in the skin. Autologous oral mucosa grafts have been employed as epithelial materials transplanted to an oral mucosal defect which is unable to suture class. This new system of autologous transplantation sheets is available for use as a tissue engineering technique in place of surgical grafting methods (87).

Human saliva contains many types of antimicrobial peptides which are secreted from salivary glands and serve to maintain to oral health as well as inhibit bacterial growth (88-89). Although rodent saliva contains large amounts of growth factors (EGF and NGF), in humans, concentrations of EGF and NGF are 100,000 times lower than in rodent saliva. Oudhoff et al. reported that histatin 1 and histatin 2 in human saliva induce major wound closing activity (90). It is known that oral mucosal wounds heal with accelerated figures with reduced scar formation compared with skin wound. Shannon et al. reported that oral fibroblasts induced enhanced collagen gel contraction, yet lower levels of $\alpha$-SMA, and they also produced significantly greater levels of both KGF and HGF than their dermal cells (91). Those results indicate phenotypic differences between oral and dermal fibroblasts that may well contribute to differences in healing wounds, both oral and cutaneous.

The reports regarding wound healing of the nasal and paranasal mucosa have not been sufficiently confirmed. Watelet et al. reported that wound healing in nasal and paranasal mucosa is a highly coordinated process involving inflammatory reaction, immune response, specific clot formation and finally tissue remodeling (92). Levels of NGF increase after allergen challenge and mast cells are the main source of human nasal NFG. NGF expression (immunofluorescence) is the strongest in the submucosal glands and lesser in epithelia, and both NGFRs are localized not only on nerves, and also in nasal epithelium and in submucosal glands. The result suggests that NGF and NGFRs participate in the pathophysiology of nasal allergies (93). In sinus epithelial cells, NGF $(20-50 \mathrm{ng} / \mathrm{ml})$ significantly decreased the wound area to $<40 \%$ compared with controls that were still $70 \%$ of their original sizes in a 24 hrs wound. NGF accelerated in vivo epithelial wound closure while NGF and KGF reduced fibroblast proliferation (94).

\section{Corneal wound healing}

The cornea is virtually avascular tissue and it has very dense innervation (40 times more than tooth pulp and 400 times more than skin) (95). Thus, inflammatory reaction and subsequent healing process are controlled by neuronal innervation, and the maintenance of corneal tissue with NGF treatment suggests that treatment completely restores innervation of the cornea. The standard treatments consist of covering the eye with a soft contact lens, constructing a conjunctive imitation flap or transplantation of skin or oral epithelia. However, the outcome is often severely impaired 
vision. NGF receptors have been observed on the normal and injured cornea and conjunctiva (96-97). Throughout epithelial proliferation, all patients had photophobia and burning of their eyes during slit-lamp examination and most patients had improved corneal sensitivity, suggesting functional recovery of the corneal innervation. Recovery of photovision may be related to the ability of NGF to induce neuritic sprouting by neuronal cells, but not regeneration in vivo. In corneal tissue, inflammatory reaction and healing are controlled by neuronal innervation by NGF, and corneal nerve damage injury induces severe alterations in the metabolism and vitality of the epithelium, and surgical or chemical damage of corneal innervation impairs epithelial healing and then induces trophic ulcers.

Transcription of NGF, NT-3, BDNF and NGFR (trkA, $\operatorname{trk} B, t r k C, t r k E)$ in the rabbit cornea was reportedly detected both ex vivo and in the epithelium and stroma in culture. Transcription of NT-4 was only expressed in the epithelium, while the transcription of GDNF was in the stroma. Levels were high in NT-3, NT-4 and trk receptor and low in NGF, BDNF and GDNF. NGF and GDNF stimulate corneal epithelial proliferation (98).

Topical NGF treatment in patients with corneal injuries has become mainstream. Italian investigators have indicated that NGF promotes corneal healing $(99,100)$. In 2006, two papers reported the NGF effect on human fibroblastickeratinocytes and the possible mechanism of corneal healing $(101,102)$. NGF have pleiotropic modulators in wound healing and inflammatory responses, such as NGF, TrkA ${ }^{\text {NIGFR }}$, and $\mathrm{P} 75^{\mathrm{NTP}}$, and they are expressed in corneal epithelial cells and keratinocytes, and NGF locally applied induces healing of neurotrophic or autoimmune corneal ulcer. NGF was able to induce fibroblastic and keratinocytic differentiation into myofibroblast migration. This result shows that the topical administration of NGF is effective in accelerating corneal wound healing following surgery (102).

The biological effect of NGF is mediated by the presence of receptors located on the surface of corneal and conjunctival cells. In an experiment involving cataract surgery $(n=30)$, group A patients received 1 drop of NGF solution (10 $\mu \mathrm{g}$ NGF) in the conjunctival fornix every $2 \mathrm{hrs}$ for 2 weeks and 4 times a day for another weeks. Group B patients received a drop of hyaluronic acid at the same time as group A patients. Optical coherence tomography (OCT) was used to measure corneal thickness at the side of the surgical wound. The clinical experience of the study showed that topical administration of NGF is effective in accelerating the healing of corneal wound (102). Conservative treatment of corneal ulcers has been reported regarding the use of NGF, which is effective evidence in congenital neurotrophic corneal ulcers (103). Neurotrophic keratopathy is a degenerative corneal disease caused by impairment of the trigeminal nerves which leads to a corneal epithelial effect, ulcer formation and proliferation. Topical application of NGF induces complete ulcer healing and recovery of corneal sensibility (104). More recently, Aloe et al, of the same group of the Italian National Research Council, reported that clinical evidence suggests the topical application of NGF promotes wound healing without side effects on corneal and cutaneous tissue damages (105). It is noted that nicergoline promoted corneal wound healing in rat eyes, and that the effect is likely to be related to increased NGF in the corneas and lacrimal gland secretion (106).

For reconstruction of ocular surface damage, non-ocular epithelium, as cultivated autologous oral mucosal epithelium transplanted to damaged ocular surface, is described in 4 patients with Steven-Johnson syndrome and 3 patients with chemical burns, where it was successfully applied $(87,107)$. Although this report does not use NGF, it is suggested that cultivated oral mucosal epithelium transplantation might promote the healing process by local application of NGF.

\section{Skin wound healing}

It has been speculated that NGF might have a biological role in the process of skin wound healing. Among the ancient Greeks, snake saliva (containing NGF and sarafotoxins) used for human treatment achieved significantly fast wound closure. Since the discovery of the mammalian endotoxins, the sarafotoxins from snake venom have been reported to have a toxic effect on living bodies and also the substitution is found in the vasoactive intestinal contractor peptide (VIC) and high binding affinity to cardiovasculature (108-109). Endothelin is a natural component of the mammalian vascular system, while sarafotoxin is a highly toxic component of snake venom. Sarafotoxins are classified into three isotoxins; S6a1, S6b and S6c, with strong cardiotoxic activity (110). Physiological roles of NGF in saliva have been reported to enhance wound healing in similar mechanisms (111). Thus, topical application of NGF to an open wound may have effective wound healing. NGF receptor TrkA immunostaining was limited to basal epithelial cells of the skin. Expression of NGFRs (trkA, $p 75^{\mathrm{NTR}}$ ) is decreased following acute inflammatory stimulus and in association with chronic inflammatory dermatitis (112). Cutaneous and mucosal wounds in patients with diabetes mellitus (DM) or experimentally-induced DM animals have delayed the healing process or occasionally caused infection. Impaired production of NGF has been reported in submandibular glands of diabetic mice (113). Peripheral neuropathy that occurs by a complicated mechanism is one of the common symptoms of DM patients that sensory neurons presents as pain or loss of sensation and impaired wound healing. Decreased levels of NGF and substance P in the skin of patients with DM, give rise to the possibility of pathogenesis of peripheral neuropathy of DM. Matsuda et al. examined the wound healing processes compared to normal and DM mice (114). Sialectomized mice had reduced NGF in sera, and normal mice showed increased NGF in sera and in wounded skin tissue. NGF and mRNA were detected regenerating epithelial and mesenchymal tissues at the edge of wounds, suggesting NGF was produced at the wound edge. Topical application of NGF into wounds accelerated wound healing in mice. The experimental results suggest that NGF contributes to wound healing by local NGF released from wounded tissue in both normal and DM mice. NGF and NGFR have been noted as a reparative factor 
for new innervation and also neo-vascularizating functions, because scar formation after tissue injuries is due to overproduction of connective tissue collagen without formation of new microvessels and associated peripheral nervous fibers. Desmouliere et al. reported that the regulation of apoptotic phenomena during wound healing may be important in scar establishment and development of pathobiological scarring (115). However, the authors did not document the nerve remodeling associated with NGF and NGFR. Effects of NGF on fibroblast migration and proliferation, collagen formation, and modulation in myofibroblasts were found to produce NGF and to express TrkA receptor, and P75 receptor was only expressed after NFG exposure. NGF significantly induced skin and lung fibroblast migration, but NGF did not influence skin or lung fibroblast proliferation, collagen production, or metalloproteinase activation. Fibrous tissue in human skin and lungs showed immunohistochemically detectable NGF, TrkA, and P75, suggesting a direct pro-fibrogenic effect of NGF on skin and the lung fibroblast, thereby indicating the role of NGF in tissue remodeling and fibrosis (116). NGF incorporating collagen in wound healing has been reported in rats. The NGF incorporated in collagen-treated rats showed a shorter duration of healing with an increased rate of wound contraction. The results indicate that topical application of NGF enhanced the rate of wound healing (117).

Excessive scarring is the result of increased collagen production and reduced collagen breakdown, in which those cells, scar tissue and growth factors involved in immunological and inflammatory process play important roles. Hypertrophic scar formation was significantly associated with an increased number of epidermal Langerhans cells, and it significantly increased expression of epidermal IL-4. No relationship was found between mast cells, T cells and macrophage NGF production in those cells, and IFN formation of normal or hypertrophic scars. Those results indicate that the epidermal immune barrier plays an important role in the development of hypertrophic scar formation (118).

The effect of topical application of NGF on nerve ending regeneration of large skin grafts in patients has also been examined in PGP (protein gene product) 9.5, synaphtophysin and neuron specific enolase. Local application of NGF could promote nerve generation and sensory recovery of grafted skin (119). It is known that innervation participates in normal ligament healing as well as skeletal muscle remodeling. Local application of NGF can improve ligament healing by promotion of both re-innervation and angiogenesis, and results in scars with enhanced mechanical properties (120). Such evidence may offer suggestions for treatment following reconstructive surgery with the use of myocutaneous flaps in head and neck surgery.

\section{Burn, pressure, crush wound and ulcer}

The therapeutic method for burn wounds has changed in recent decades. Jurjus et al. recently noted that the effect of silver sulfadiazine and moist exposed burn ointment (ME130), a recently described burn ointment of herbal origin, on mast cells and several wound healing growth factors and cytokines (bFGF, TGF- $\beta$, NGF, IL- 1 ) in rabbit skin (121). This experiment dealt with novel strategies of wound healing as a topical application of several growth factors. The clinical approach for burn wounds has been aggressive surgery with early tangential excision; wound closure is performed, leading to improvement in mortality rates of burn victims. Skin grafting, autologous or cultured skin, or mucosal grafting is used with of NGF (122). As for topical application of NGF on pressure ulcers, it was first reported that NGF might be an effective therapy for patients with pressure ulcers (123). Pressure ulcers in nursing homes are common problems associated with significant morbidity and mortality. Preventive measures should be implemented early, and a multidisciplinary nursing home team is essential for prevention and special treatment (124). Topical application of NGF may be an effective therapy for patients with pressure ulcers. A total of 36 patients (n18 received NGF, the other $n 18$ received conventional topical treatment) were thus treated in a study conducted in Rome (125).

NGF reportedly influences endothelial cell proliferation and angiogenetic activity. Chiaretti et al. reported on the subcutaneous administration of highly-purified murine NGF in a child with severe crush syndrome of the lower limbs (126). NGF $10 \mu \mathrm{g}$ was injected subcutaneously every $8 \mathrm{hrs}$ for 7 days into an extensive ischemic skin lesion of the calcaneal area. After local injection, the patient showed gradual improvement of the ischemic skin, no side effects were observed, and the child was discharged in good condition to await a limited calcaneal escharotomy. It is interesting to note that collagen-binding human NGF- $\beta$ could be used to target nerve cells and improve the regeneration. In the rat sciatic nerve crush injury model, collagen-binding NGF could be retained and concentrated at the nerve-injured site to promote nerve repair and enhance function recovery following nerve damage (127). This method may be applied to mandibular nerve injury after tooth extraction or wisdom teeth extraction, or following mandibular fractures.

\section{NGF and diabetic neuropathy and diabetic ulcers}

It is known that NGF deprivation produces hyperalgesia and NGF expression leads to hypoalgesia. Immunohistochemical reaction of NGF is depleted in keratinocytes in diabetic skin. A decrease in skin NGF influences the presentation of diabetic polyneuropathy (128). The results of clinical studies of 250 patients with diabetic polyneuropathy suggest that recombinant human NGF is safe, based on use in patients with symptomatic diabetic polyneuropathy (129130). NGF and NGFRs involve a surprising variety of neurons, glia, and nonneural tissues, and NGF signaling subserves neuroprotective and repair functions. NGF signaling may enhance neurological disorders, neuroprotection and neural repair (131). Yiangou et al. reported that immunostaining of both rhNGF and preproNGF was reactive in basal keratinocytes in normal human skin, and rat skin showed an accumulation of nerve fibers distal to sciatic nerve ligation (132). It is suggested that preproNGF may be 
preferentially taken up and transported by P75 ${ }^{\mathrm{NTR}}$. Diabetes patients $(n=3)$ with leg or foot ulcers unresponsive to conventional therapies were reportedly treated with topical application of NGF. NGF may thus represent a powerful new regimen for treatment of difficult diabetic ulcers (133).

\section{Allergy and inflammation}

Frossard et al. reviewed NGF and NGFR in bronchial epithelium as asthma and inflammation, and reported that NGF may induce bronchial hyper-responsiveness (134). An important feature of asthma is increasing sensory innervations. Increased NGF expression and release develop in asthma patients after bronchial provocation with allergen. NGF and NGFR may also induce migration and activation of inflammatory cells which infiltrate bronchial mucosa including epithelia, smooth muscle of bronchus and pulmonary fibrosis. Thus, asthma is a complex feature as the neuro-immune cross-talk involved in chronic inflammatory airway diseases. A similar concept of atopic dermatitis has been noted in the increased plasmas levels of NGF and substance $\mathrm{P}$ (SP) in allergic human skin diseases (135). The investigators suggested that neurogenic factors systemically modulate the allergic response in atrophic dermatitis, probably through interactions with immune inflammatory factors of substances. It is noted that NGF and SP may be useful markers of disease activity in patients with atopic disease. Two basic studies on the relation to neuro-immuno modulation in allergic phenomena have been reported. The first is a regulatory function for NGF, SP and CGRP in sensory nerves innervating inflamed tissue (136), and the second is that a keratinocyte-derived NGF plays a role in autocrine epidermal cell proliferation. Di Marco et al. reported that effects of NGF as survival and differentiation factors in keratinocytes, were a potent regulator of cell proliferation, at least in human epithelial cells (137).

\section{Conclusion}

\section{Wound healing and NGF-NGFR}

A variety of growth factors are well known to enhance wound healing in animals and humans. However, the wound healing processes in humans are still not fully understood. Experience has shown that the healing process in oral mucosal wounds is faster than in skin wounds. A large variety of growth factors and biologically active peptides are synthesized and secreted by salivary and lacrimal glands in animals and humans. The best-known growth factors are EGF and NGF, which are secreted in the mouse submandibular glands, release factors into saliva and are absorbed from gastric and intestinal epithelium into blood serum. Urogastron as human EGF enhances the healing process in gastric ulcers. Recent studies have shifted to try growth factor research in order to better understand remodeling processes. The present review pointed out that NGF and NGFR are responsible to cells of both epithelial and mesenchymal origin, thereby accelerating wound closure or tissue remodeling.

\section{Secreted NGF in salivary and lacrimal glands enhanced wound healing}

The remodeling process of epithelial-lined tissues in the human is influenced by secretory materials such as salivary mucin, tear and other materials including growth factors, cytokines and antimicrobial peptides for defense mechanism. Previous studies regarding wound healing have described mainly the tissue proliferating process from a histopathological standpoint with attention to the key roles of NGF and NGFR. NGFR was expressed in the basal cells of the stratified squamous epithelium, and NGFR also expressed in wound edge and continuously expressed newly proliferating keratinocytes in the wound. Thus peripheral innervation in healing wounds was accelerated and wound closure was promoted.

\section{NGF and NGFR in clinical usage}

The present report reviewed biological roles of NGF and NGFR in wound tissues from an early stage to the remodeling stage in the skin, oral-paranasal mucosa and cornea. Cell regeneration as a final remodeling has been discussed in relation to the biological mechanism of EGF and EGFR in pressure wounds and diabetic complicated ulcers. The results will be beneficial for topical clinical use of NGF derivatives under wet conditions, such as promoting tissue repair.

During mandibular distraction osteogenesis the inferior alveolar nerve (iaN) is in someone damaged. Immunohistochemical reactions of $\mathrm{P} 75$ receptor were found to be significantly elevated at 7 and 14 days in Schwann cells located in the outer of axon in the iaN, but were almost unstained at 28 and 56 days. Co-expression of NGF and P53 receptor was detected at 7 and 14 days. It is concluded that P75 receptor plays an important role on remyelination due to abundant expression in Schwann cells of injured nerves (138). Nerve damage following tooth extraction, also expresses NGF receptor (P75), and therapeutic approach to iaN injuries may benefit from topical application of NGFR.

\section{Acknowledgment}

This study was supported in part by a Grants-in-Aid for Scientific Research (C) (No. 19592273 and No. 23592909) from the Japan Society for the Promotion of Science and "High-Tech Research Center" Project for Private Universities: Matching Fund Subsidy from MEXT (Ministry of Education, Culture, Sports, Science and Technology), 2007-2011.

\section{References}

1. Discher DE, Mooney DJ, Zandatra PW: Growth factors, materials, and forces combine and control stem cells. Science 2009; 324: 1673-7.

2. Zelles T, Purushotham KR, Macauley SP, Oxford GE, Humphreys-Beher MG. Saliva and growth factors: the fountain of youth resides in us all. J Dent Res 1995; 74: 1826-32. 
3. Levi-Montalcini R. The nerve growth factor 35 years later. Science 1987; 237: 1154-62.

4. Stappenbeck TS, Miyoshi H. The role of stromal stem cells in tissue regeneration and wound repair. Science 2009; 324: 1666-9.

5. Rüdiger K, Shugian J, Venkata N, Edward O, Mariano B. The trk proto-oncogene encodes a receptor for nerve growth factor. Cell 1991; 65: 189-97.

6. Ebendal T. Function and evolution in the NGF family and its receptors. J Neurosci Res 1992; 32: 461-70.

7. Yamamoto M, Sobue G, Yamamoto K, Terao S, Mitsuma T. Expression of mRNAs for neurotrophic factors (NGF, BDNF, NT-3, and GDNF) and their receptors (p75ngfr , TrkA, TrkB, and TrkC) in the adult human peripheral nervous system and nonneural tissues. Neurochemical Res 1996; 21: 929-38.

8. Jacobs JS, Miller MW. Expression of nerve growth factor, p75, and the high affinity neurotrophin receptors in the adult rat trigeminal system: Evidence for multiple trophic support systems. J Neurocytology 1999; 28: 571-95.

9. Niederhauser O, Mangold M, Schubenel R, Kusznir EA, Schmidt D, Hertel C. NGF ligand alters NGF signaling via p75 (NTR) and trkA. J Neurosci Res 2000; 61: 263-72.

10. Peters EMJ, Stieglitz MG, Liezman C et al. p75 Neurotrophin receptor-mediated signaling promotes human hair follicle regression (Catagen). Neurobiology 2006; 168: 221-34.

11. Mischel PS, Smith SG, Vining ER, Valletta JS, Mobley WC, Reichardt LF. The extracellular domain of p75NTR is necessary to inhibit neurotrophin-3 signaling through TrkA. J Biol Chem 2001; 276: 11294-301.

12. Esposito D, Patel P, Stephenes RM et al. The cytoplasmic and transmembrane domains of the p75 and Trk A receptors regulate high affinity binding to nerve growth factor. J Biol Chem 2001; 276: 32687-95.

13. Shibayama E, Koizumi H. A new role for neurotrophins: involvement of brain-derived neurotrophic factor and neurotrophin-4 in hair cycle control. Am J Pathol 1996; 148: $1807-18$.

14. Micera A, Lambiase A, Srampachiacchiere B, Bonini S, Bonini S, Levi-Schaffer F. Nerve growth factor and tissue repair remodeling: trk $\mathrm{A}^{\mathrm{NGFR}}$ and $\mathrm{p} 75^{\mathrm{NTR}}$, two receptors one fate. Cytokine Growth Factor Rev 2007; 18: 245-56.

15. Botchkarev VA, Botchkareva NV, Welker P et al. Cellular localization of the Trk neurotrophin receptor family in human non-neuronal tissues. FASEB J 1999; 13: 395-410.

16. Yan C, Liang Y, Nylander KD, Schor NF. Individual and combined effects of TrkA and p75NTR nerve growth factor receptors. A role for the high affinity receptor site. Cancer Res 2002; 62: 4867-75.

17. Lad SP, Peterson DA, Bradshaw RA, Neet KE. Individual and combined effects of TrkA and p75NTR nerve growth factor receptors. A role for the high affinity receptor site. $J$ Biol Chem 2003; 278: 24808-17.

18. Yaar M, Eller MS, DiBenedetto P et al. The trk family of receptors mediates nerve growth factor and neurotrophin-3 effects in melanocytes. J Clin Invest 1994; 94: 1550-62.

19. Huston JM, Niall M, Evans D, Fowler R. Effect of salivary glands on wound contraction in mice. Nature 1979; 279: 793-5.
20. Murphy RA, Saide JD, Blanchard MH, Young M. Nerve growth factor in mouse serum and saliva: ole of the submandibular gland. Biochemistry 1977; 74: 2330-3.

21. Gregory H. Isolation and structure of urogastrone and its relationship to epidermal growth factor. Nature 1975; 257: 325-7.

22. Hadjiconstantinou M, McGuire L, Duchemin AM et al. Changes in plasma nerve growth factor levels in older adults associated with chronic stress. $J$ neuroimmunol 2001; 116: 102-6.

23. Levi-Montalcini R, Aloe L, Mugnaini E, Oesch F, Thoenen $H$. Nerve growth factor induces volume increase and enhances tyrosine hydroxylase synthesis in chemically axotomized sympathetic ganglia of newborn rats. Proc Natl Acad Sci USA 1975; 72: 595-9.

24. Miller DA, Lee A, Matsui Y, Chen EY, Moses HL, Derynck R. Complementary DNA cloning of the murine transforming growth factor-beta 3 (TGF beta 3 ) precursor and the comparative expression of TGF beta 3 and TGF beta 1 messenger RNA in murine embryos and adult tissues. Mol Endocrinol 1989; 3: 1926-34.

25. Fischer HP, Eich W, Russell IJ. A possible role for saliva as a diagnostic fluid in patients with chronic pain. Semin Arthritis Rheum 1998; 27: 348-59.

26. Ruhl S, Hamberger S, Betz R et al. Salivary proteins and cytokines in drug-induced gingival overgrowth. J Dent Res 2004; 83: 322-6.

27. Nam JW, Chung JW, Kho HS, Chung SC, Kim YK. Nerve growth factor concentration in human saliva. Oral Dis 2007; 13: 187-92.

28. Komatsu K, Hasegawa H, Honda T, Yabashi A, Kawasaki T. Nerve growth factors in saliva stimulated by mastication. Oral Science Int 2008; 5: 78-84.

29. Mori M. Histochemistry of the salivary glands. CRC Press. Boca Raton, Ann Arbor Boston 1991: 221-32.

30. Rosenbaum T, Vidaltamayo R, Sánchez-Soto MC, Zentella A, Hiriart M. Pancreatic beta cells synthesize and secrete nerve growth factor. Proc Natl Acad Sci USA 1998; 95: 7784-8.

31. Mathers WD. Why the eye becomes dry: a cornea and lacrimal gland feedback model. CLAO J 2000; 26: 159-65.

32. Nguyen DH, Beuerman RW, Thompson HW, DiLoreto DA. Growth factor and neurotrophic factor mRNA in human lacrimal gland. Cornea 1997; 16: 192-9.

33. Wilson SE, Liang Q, Kim WJ. Lacrimal gland HGF, KGF, and EGF mRNA levels increase after corneal epithelial wounding. Invest Ophth Vis Sci 1999; 40: 2185-90.

34. Zhao J, Nagasaki T, Maurice DM. Role of tears in keratocyte loss after epithelial removal in mouse cornea. Invest Ophth Vis Sci 2001; 42: 1743-9.

35. Lambiase A, Bonini S, Micera A, Rama P, Bonini S, Aloe L. Expression of nerve growth factor receptors on the ocular surface in healthy subjects and during manifestation of inflammatory diseases. Invest Ophthalmol Vis Sci 1998; 39: $1272-5$.

36. Micera A, Puxeddu I, Lambiase A et al. The pro-fibrogenic effect of nerve growth factor on conjunctival fibroblasts is mediated by transforming growth factor-beta. Clin Exp Allergy 2005; 35: 650-6.

37. Woo HM, Bentley E, Campbell SF, Marfurt CF, Murphy 
CJ. Nerve growth factor and corneal wound healing in dogs. Exp Eye Res 2005; 5: 633-42.

38. Flour M, Degreef H. Pharmacological treatment of wounds. Semin Cutan Med Surg 1998; 17: 260-5.

39. Diegelmann RF, Evans MC. Wound healing: An overview of acute, fibrotic and delayed healing. Front Biosci 2004; 9: 283-9.

40. Tomasek JJ, Gabbiani G, Hinz B, Chaponnier C, Brown RA. Myofibroblasts and mechano: Regulation of connective tissue remodeling. Nat Rev Mol Cell Biol 2002; 3: 349-63.

41. Atiyeh BS, Al-Amm CA, El-Musa KA, Sawwaf A, Dham $\mathrm{R}$. The effect of moist and moist exposed dressings on healing and barrier function restoration of partial thickness wounds. European Journal of Plastic Surgery 2003; 26: 5-11.

42. Atiyeh BS, Amm CA, El Musa KA. Improved scar quality following primary and secondary healing of cutaneous wounds. Aesthetic Plast Surg 2003; 27: 411-7.

43. Jiang S, Zavitz CCJ, Wang J et al. Non-adenine based purines accelerate wound healing. Purinergic Signal 2006; 2: $651-61$.

44. Aloe L, Levi-Montalcini R. Mast cells increase in tissues of neonatal rats injected with the nerve growth factor. Brain Res 1977; 133: 358-66.

45. Matsuda H, Kannan Y, Ushio H et al. Nerve growth factor induces development of connective tissue-type mast cells in vitro from murine bone marrow cells. J Exp Med 1991; 174: 7-14.

46. Mazurek N, Weskamp G, Otten U. Nerve growth factor induces growth and differentiation of human B lymphocytes. Proc Natl Acad Sci U S A 1989; 86: 10059-63.

47. Pearce FL, Thompson HL. Some characteristics of histamine secretion from rat peritoneal mast cells stimulated with nerve growth factor. J Phisiol 1986; 372: 379-93.

48. Bischoff SC, Dahinden CA. Effect of nerve growth factor on the release of inflammatory mediators by mature human basophils. Blood 1992; 79: 2662-9.

49. Kawamoto K, Okada T, Kannan Y, Ushio H, Matsumoto M, Matsuda H. Nerve growth factor prevents apoptosis of rat peritoneal mast cells through the trk proto-oncogene receptor. Blood 1995; 86: 4638-44.

50. Egozi EI, Ferreira AM, Burns AL, Gamelli RL, Dipietro LA. Mast cells modulate the inflammatory but not the proliferative response in healing wounds. Wound Repair Regen 2003; 11: 46-54.

51. Maurer M, Theoharides T, Granstein RD et al. What is the physiological function of mast cells? Exp Dermatol 2003; 12: 886-910.

52. Trautmann A, Toksoy A, Engelhardt E, Bröcker EB, Gillitzer R. Mast cell involvement in normal human skin wound healing: expression of monocyte chemoattractant protein- 1 is correlated with recruitment of mast cells which synthesize interleukin-4 in vivo. J Pathol 2000; 190: $100-6$.

53. Micera A, Puxeddu I, Aloe L, Levi-Schaffer F. New insights on the involvement of nerve growth factor in allergic inflammation and fibrosis. Cytokine Growth Factor Rev 2003; 14: 369-74.

54. Micera A, Lambiase A, Aloe L, Bonini S, Levi-Schaffer F,
Bonini S. Nerve growth factor involvement in the visual system: implications in allergic and neurodegenerative diseases. Cytokine Growth Factor Rev 2004; 15: 411-7.

55. Susaki Y, Shimizu S, Katakura K et al. Functional properties of murine macrophages promoted by nerve growth factor. Blood 1996; 88: 4630-7.

56. Garaci E, Caroleo MC, Aloe L et al. Nerve growth factor is an autocrine factor essential for the survival of macrophages infected with HIV. Mcrophage 1999; 96: 14008-13.

57. Aloe L, Alleva E, Böhm A, Levi-Montalcini R. Aggressive behavior induces release of nerve growth factor from mouse salivary gland into the bloodstream. Proc Natl Acad Sci USA 1986; 83: 6184-7.

58. Otten U, Ehrhard P, Peck R. Nerve growth factor induces growth and differentiation of human B lymphocytes. Proc Natl Acad Sci USA 1989; 86: 10059-63.

59. Kannan Y, Ushio H, Koyama $\mathrm{H}$ et al. $2.5 \mathrm{~S}$ nerve growth factor enhances survival, phagocytosis, and superoxide production of murine neutrophils. Blood 1991; 77: 1320-5.

60. Kawamoto K, Okada T, Kanan Y, Ushio H, Matsumoto M, Matsuda H. Nerve growth factor prevents apoptosis of rat peritoneal mast cell through the trk proto-oncogene receptor. Blood 1995; 86: 4638-44.

61. Ehrhard PB, Erb P, Graumann U, Otten U. Expression of nerve growth factor and nerve growth factor receptor tyrosine kinase Trk in activated CD4-positive T-cell clones. Proc Natl Acad Sci USA 1993; 90: 10984-8.

62. Torcia M, Bracci-Laudiero L, Lucibello $\mathrm{M}$ et al. Nerve growth factor is an autocrine survival factor for memory B lymphocytes. Cell 1996; 85: 345-56.

63. Pozza M, Guerra M, Manzini E, Calza L. A histochemical study of the rheumatoid synovium: focus on nitric oxide, nerve growth factor high affinity receptor, and innervation. J Rheumatol 2000; 27: 1121-7.

64. Tuveri M, Generini S, Matucci-Cerinic M, Aloe L. NGF, a useful tool in the treatment of chronic vasculitic ulcers in rheumatoid arthritis. Lancet 2000; 18: 1739-40.

65. Mogi M, Kondo A, Kinpara K, Togari A. Anti-apoptotic action of nerve growth factor in mouse osteoblastic cell line. Life Sci 2000; 67: 1197-206.

66. Nakanishi T, Takahashi K, Aoki C, Nishikawa K, Hattori T, Taniguchi S. Expression of nerve growth factor family neurotrophins in a mouse osteoblastic cell line. Biochem Biophys Res Commun 1994; 198: 891-7.

67. Hammes HP, Federoff HJ, Brownlee M. Nerve growth factor prevents both neuroretinal programmed cell death and capillary pathology in experimental diabetes. $\mathrm{Mol} \mathrm{Med}$ 1995; 1: 527-34

68. Lomen-Hoerth C, Shooter EM. Widespread neurotrophin receptor expression in the immune system and other nonneuronal rat tissues. J Neurochem 1995; 64: 1780-9.

69. Samii A, Unger J, Lange W. Vascular endothelial growth factor expression in peripheral nerves and dorsal root ganglia in diabetic neuropathy in rats. Neurosci Lett 1999; 262: 159-62.

70. Calzà L, Giardino L, Giuliani A, Aloe L, Levi-Montalcini R. Nerve growth factor control of neuronal expression of angiogenetic and vasoactive factors. Proc Natl Acad Sci USA 2001; 98: 4160-5.

71. Nissen NN, Polverini PJ, Koch AE, Volin MV, Gamelli RL, 
DiPietro LA. Vascular endothelial growth factor mediates angiogenic activity during the proliferative phase of wound healing. Am J Pathol 1998; 152: 1445-52.

72. Khan KM, Falcone DJ, Kraemer R. Nerve growth factor activation of Erk-1 and Erk-2 induces matrix metalloproteinase-9 expression in vascular smooth muscle cells. $J$ Biol Chem 2002; 277: 2353-9.

73. Raychaudhuri SK, Raychaudhuri SP, Weltman H, Farber EM. Effect of nerve growth factor on endothelial cell biology: proliferation and adherence molecule expression on human dermal microvascular endothelial cells. Arch Dermatol Res 2001; 293: 291-5.

74. Tanaka A, Wakita U, Kanmbe N, Iwasaki T, Matsuda H. An autocrine function of nerve growth factor for cell cycle regulation of vascular endothelial cells. Biochem Bioph Res Co 2004; 313: 1009-14.

75. Nico B, Mangieri D, Benagiano V, Crivellato E, Ribatti D. Nerve growth factor as an angiogenetic factor. Microvasc Res 2008; 75: 135-41.

76. Marco ED, Mardhisio PC, Bondanza S, Franzi T, Cancedda $\mathrm{R}$, Luca MD. Growth-regulated synthesis secretion of biologically active nerve factor by human keratinocytes. $J$ Biol Chem 1991; 32: 21718-22.

77. Pincelli C, Sevignani C, Manfredini R et al. Expression and function of nerve growth factor and nerve growth factor receptor on cultured keratinocytes.J Invest Dermatol 1994; 103: 13-8.

78. Paus R, Luftl M, Czarnetzki BM. Nerve growth factor modulates keratinocyte proliferation in murine skin organ culture. Br J Dermatol 1994; 130: 174-80.

79. Yaar M, Grossman K, Eller M, Gilchrest BA. Evidence for nerve growth factor-mediated paracrine effects in human epidermis. J Cell Biol 1991; 115: 821-8.

80. Pincelli C, Yaar M. Nerve growth factor: its significance in cutaneous biology. J Investig Dermatol Symp Proc 1997; 2: 31-6.

81. Marconi A, Vaschieri C, Zanoli S, Giannetti A, Pincelli C. Nerve growth factor protects human keratinocytes from ultraviolet-B-induced apoptosis. J Invest Dermatol 1999; 113: 920-7.

82. Beales MP, Funderburgh JL, Jester JV, Hassell JR. Proteoglycan synthesis by bovine keratocytes and corneal fibroblasts: maintenance of the keratocyte phenotype in culture. Invest Ophthalmol Vis Sci 1999; 40: 1658-63.

83. Kohyama T, Liu X, Wen FQ et al. Nerve growth factor stimulates fibronectin-induced fibroblast migration. $J$ Lab Clin Med 2002; 140: 329-35.

84. Sonis ST. Mucositis. The impact, biology and therapeutic opportunities of oral mucositis. Oral Oncol 2009; 45: 1015-20.

85. Fujisawa K, Miyamoto Y, Nagayama M. Basic fibroblast growth factor and epidermal growth factor reverse impaired ulcer healing of the rabbit oral mucosa. J Oral Pathol Med 2003; 32: 358-66.

86. Hayashi K, Storesund T, Schreus O et al. Nerve growth factor $\beta /$ pro-nerve growth factor and their receptors in normal human oral mucosa. Eur J Oral Sci 2007; 115: 344-54.

87. Amemiya $T$, Nakamura $T$, Yamamoto $T$, Kinoshita $S$, Kanamura N. Immunohistochemical study of oral epithelial sheets cultured on amniotic membrane for oral mucosal reconstruction. Biomed Mater Eng 2010; 20: 37-45.

88. Mori M, Takeuchi H, Sato M, Sumitomo S. Anti microbial peptides in saliva and salivary glands. Oral Med Pathol 2006; 11: 11-7.

89. Mori M, Sumitomo S, Shrestha P, Tanaka S, Takai Y, Shikimori M. Multifunctional roles of growth factors or biologically active peptides in salivary glands and saliva. Oral Med Pathol 2008; 12: 115-23.

90. Oudhoff MJ, Bolscher JGM, Nazmi K et al. Histatins are the major wound-closure stimulating factors in human saliva as identified in a cell culture assay. Faseb J 2008; 22: 3805-12.

91. Shannon DB, McKeown STW, Lundy FT, Irwin CR. Phenotypic differences between oral and skin fibroblast in wound contraction and growth factor expression. Wound Repair Regen 2006; 14: 172-8.

92. Watelet JB, Bachert C, Gevaert P, Van Cauwenberge P. Wound healing of the nasal and paranasal mucosa: a review. Am J Rhinol 2002; 16: 77-84.

93. Wu X, Myers AC, Goldstone AC, Togias A, Sanico AM. Localization of nerve growth factor and its receptors in the human nasal mucosa. J Allergy Clin Immunol 2006; 118: 428-33.

94. Tan L, Hatzirodos N, Wormald PJ. Effect of nerve growth factor and keratinocyte growth factor on wound healing of the sinus mucosa. Wound Repair Regen 2008; 16: 108-16.

95. Lambiase A, Rama P, Bonini S, Caprioglio G, Aloe L. Topical treatment with nerve growth factor for corneal neurotrophic ulcers. N Engl J Med 1998; 338: 1174-80.

96. Lambiase A, Bonini S, Bonini S et al. Increased plasma levels of nerve growth factor in vernal keratoconjunctivitis and relationship to conjunctival mast cells. Invest $\mathrm{Oph}$ thalmol Vis Sci 1995; 36: 2127-32.

97. Lambiase A, Bonini S, Aloe L, Carito G, Rama P. Expression of nerve growth factor receptors on human ocular surface. Invest Ophthalmol Vis Sci 1997; 38: S1078 (abstract).

98. You L, Kruse FE, Volcker HE. Neurotrophic factors in the human cornea. Invest Ophthalmol Vis Sci 2000; 41: 692-702.

99. Lambiase A, Manni L, Bonini S, Rama P, Micera A, Aloe L. Nerve growth factor promotes corneal healing: Structural, biochemical and molecular analyses of rat and human corneas. Invest Ophthalmol Vis Sci 2000; 41: 1063-69.

100. Bonini S, Lambiase A, Rama P, Caprioglio G, Aloe L. Topical treatment with nerve growth factor for neurotrophic keratitis. Ophthalmology 2000; 107: 1347-51.

101. Micera A, Lambiase A, Puxeddu I et al. Nerve growth factor effect on human primary fibroblastic-keratocytes: possible mechanism during corneal healing. Exp Eye Res 2006; 83: 747-57.

102. Cellini M, Bendo E, Bravetti GO, Campos EC. The use of nerve growth factor in surgical wound healing of the cornea. Ophthalmic Res 2006; 38: 177-81.

103. Tan MH, Bryars J, Moore J. Use of nerve growth factor to treat congenital neurotrophic corneal ulceration. Cornea 2006; 25: 352-5.

104. Lambiase A, Coassin M, Sposato V et al. NGF topical application in patients with corneal ulcer does not generate 
circulating NGF antibodies. Pharmacol Res 2007; 56: 65-9.

105. Aloe L, Tirassa P, Lambiase A. The topical application of nerve growth factor as a pharmacological tool for human corneal and skin ulcers. Pharmacol Res 2008; 57: 253-8.

106. Kim SY, Choi JS, Joo CK. Effects of nicergoline on corneal epithelial wound healing in rat eyes. Invest Ophthalmol Vis Sci 2000; 50: 621-5.

107. Nakamura T, Inatomi T, Sotozono C, Amemiya T, Kanamura N, Kinoshita S. Transplantation of cultivated autologous oral mucosal epithelial cells in patients with severe ocular surface disorders. Br J Ophthalmol 2004; 88: 1280-4.

108. Kloog Y, Ambar I, Sokolovsky M, Kochva E, Wollberg Z, Bdolah A. Sarafotoxin, a novel vasoconstrictor peptide: phosphoinositide hydrolysis in rat heart and brain. Science 1988; 242: 268-70.

109. Bdolah A, Wollberg Z, Fleminger G, Kochva E. SRTX-d, a new native peptide of the endothelin/sarafotoxin family. Febs Lett 1989; 256: 1-3.

110. Takasaki C, Tamiya N, Bdolah A, Wollberg Z, Kochva E. Sarafotoxins S6: several isotoxins from Atractaspis engaddensis (burrowing asp) venom that affect the heart. Toxicon 1988; 26: 543-8.

111. Li KC, Koroly MJ, Schattenkerk ME, Malt RA, Young M. Nerve growth factor: Acceleration of the rate of wound healing in mice. Proc Natl Acad Sci 1980; 77: 4379-81.

112. Bull HA, Leslie TA, Chopra S, Down PM. Expression of nerve growth factor receptors in cutaneous inflammation. Br J Dermatol 1998; 139: 776-83.

113. Kasayama S, Oka T. Impaired production of nerve growth factor in the submandibular gland of diabetic mice. $\mathrm{Am} \mathrm{J}$ Physiol 1989; 257: E400-40.

114. Matsuda H, Koyama H, Sato H et al. Role of nerve growth factor in cutaneous wound healing: Accelerating effects in normal and healing-impaired diabetic mice. J Exp Med 1998; 187: 297-306.

115. Desmouliere A, Redard M, Draby I, Grabbiani G. Apoptosis mediates the decrease in cellularity during the transition between granulation tissue and scar. Am J Pathol 1995; 146: 56-66.

116. Micera A, Vigneti E, Pickholtz D et al. Nerve growth factor displays stimulatory effects on human skin and lung fibroblasts, demonstrating a direct role for this factor in tissue repair. Proc Natl Acad Sci USA 2001; 22: 6162-7.

117. Nithya M, Suguna L, Rose C. The effect of nerve growth factor on the early response during the process of wound healing. Biochim Biophys Acta 2003; 1620: 25-31.

118. Niessen FB, Schalkwik J, Vos H, Timens W. Hyertrophic scar formation is associated with an increased number of epidermal langerhans cells. J Pathol 2004; 202: 121-9.

119. Wu ZH, Huang J, Gao WH et al. Effect of nerve growth factor on the promotion of sensory recovery of large skin graft in patients. Zhonghua Shao Shang Za Zhi 2007; 23: 440-3.

120. Mammoto T, Seerattan RA, Paulson KD, Leonard CA, Bray RC, Salo PT. Nerve growth factor improves ligament healing. J Orthop Res 2008; 26: 957-64.

121.Jurjus A, Atiyeh BS, Abdallah IM et al. Pharmacological modulation of wound healing in experimental burns. Burns
2007; 33: 892-907.

122. Atiyer BS, Hayek SN, Gunn SW. New technologies for burn wound closure and healing-Review of the literature. Burns 2005; 31: 944-56.

123. Bernabei R, Landi F, Bonini S et al. Effect of topical application of nerve-growth factor on pressure ulcers. Lancet 1999; 354: 307. (Abstract)

124. Smith DM. Pressure ulcers in the nursing home. Ann Intern Med 1995; 123: 433-42.

125. Landi F, Aloe L, Russo A et al. Topical treatment of pressure ulcers with nerve growth factor: A randomized clinical trial. Ann Intern Med 2003; 139: 635-41.

126. Chiaretti A, Piastra M, Caresta E, Nanni L, Aloe L. Improving ischaemic skin revascularisation by nerve growth factor in a child with crush syndrome. Arch Dis Child 2002; 87: 446-8.

127. Sun W, Sun C, Lin $\mathrm{H}$ et al. The effect of collagen-binding NGF- $\beta$ on the promotion of sciatic nerve regeneration in a rat sciatic nerve crush injury model. Biomaterials 2009; 30: $4649-56$

128. Anand P, Terenghi G, Warner G, Kopelman P, WilliamsChestnut RE, Sinicropi DV. The role of endogenous nerve growth factor in human diabetic neuropathy. Nat Med 1996; 2 : 703-7.

129. Apfel SC, Kessler JA, Adornato BT, Litchy WJ, Sanders C, Rask CA. Recombinant human nerve growth factor in the treatments of diabetic polyneuropathy. Neurology 1998; 51: 695-702.

130. Apfel SC. Nerve growth factor for the treatment of diabetic neuropathy: What went wrong, what went right, and what does the future hold? Int Rev Neurobiol 2002; 50: 393-413.

131. Sofroniew MV, Howe CL, Mobley WC. Nerve growth factor signaling, neuroprotection, and neural repair. Annu Rev Neurosci 2001; 24: 1217-81.

132. Yiangou Y, Facer P, Sinicropi DV et al. Molecular forms of NGF in human and rat neuropathic tissues: Decreased NGF precursor-like immunoreactivity in human diabetic skin. $J$ Peripher Nerv Syst 2002; 7: 190-7.

133. Generini S, Tuveri MA, Matucci Cerinic M, Mastinu F, Manni L, Aloe L. Topical application of nerve growth factor in human diabetic foot ulcers. A study of three cases. Exp Clin Endocrinol Diabetes 2004; 112: 542-4.

134. Frossard N, Freund V, Advenier C. Nerve growth factor and its receptors in asthma and inflammation. Eur $J$ Pharmacol 2004; 500: 453-65.

135. Toyoda M, Nakamura M, Makino T, Hino T, Kagoura M, Morohashi M. Nerve growth factor and substance $\mathrm{P}$ are useful plasma markers of disease activity in atopic dermatitis. Br J Dermatol 2002; 147: 71-9.

136. Donnerer J, Schuligoi R, Stein C. Increased content and transport of substance $\mathrm{P}$ and calcitonin gene-related peptide in sensory nerves innervating inflamed tissue: evidence for a regulatory function of nerve growth factor in vivo. Neuroscience 1992; 49: 693-8.

137. Di Marco E, Mathor M, Bondanza S et al. Nerve growth factor binds to normal human keratinocytes through high and low affinity receptors and stimulates their growth by a novel autocrine loop. J Biol Chem 1993; 268: 22838-46.

138. Byun JH, Lee JH, Choi YJ, Kim JR, Park BW. Coexpression of nerve growth factor and p75NGFR in the 
